\title{
Transcatheter stent implantation to treat aortic coarctation in infancy
}

\author{
Andrew N Redington, Alison M Hayes, Siew Yen Ho
}

\begin{abstract}
A ten week old girl who had previously undergone a palliative procedure for the hypoplastic left heart syndrome had unrelieved aortic coarctation that did not respond to standard balloon dilatation. Complete relief of coarctation with prompt clinical improvement was achieved with placement of an $8 \mathrm{~mm}$ selfexpanding stent.

Transcatheter stent implantation may have a role in selected patients with aortic coarctation.
\end{abstract}

(Br Heart f 1993;69:80-82)

Transcatheter placement of endovascular stents in patients with peripheral and coronary artery disease has been widely reported. ${ }^{2}$ These devices have also been used to treat children and adults with congential heart disease. Transcatheter placement of stents in the arterial duct, for palliation of complex congenital heart disease, has recently been described, ${ }^{3}$ and peripheral pulmonary artery stenosis has been successfully treated by this technique. ${ }^{4}$ We report the successful treatment of postoperative aortic coarctation in a patient who had previously undergone palliative surgery for the hypoplastic left heart syndrome.

\section{Case report}

This 10 week old girl was referred on the second day of life. Cross sectional echocardiography confirmed the diagnosis of hypoplastic left heart syndrome with atresia of the mitral and aortic valves and a severely hypoplastic ascending aorta (approximately $2 \mathrm{~mm}$ diameter). There was an obligatory left to right shunt across a restrictive foramen ovale. The proximal and distal aorta were supplied by a large arterial duct. After discussion with the parents, it was decided that the child would undergo cardiac transplantation. Ductal patency was maintained with prostaglandin $E_{2}$ but she developed worsening congestive heart failure and remained ventilator dependent. Because of her worsening symptoms palliative surgery was undertaken. Briefly, this consisted of a large direct anastomosis between the main pulmonary artery and aortic arch, insertion of a fenestrated autogenous pericardial patch at the entrance of the main pulmonary artery branches, and atrial septectomy. Thus each pulmonary artery was perfused through $\frac{\overline{\bar{F}}}{\overline{\frac{1}{5}}}$ a $2.5 \mathrm{~mm}$ fenestration and the proximal and $\varnothing$ distal aorta was supplied via the pulmonary $\%$ artery through the newly created aortopul- $\overrightarrow{0}$ monary anastomosis.

The initial postoperative progress was rela- $\vec{\omega}$ tively smooth and she was extubated on the sixth postoperative day. She remained on the general ward awaiting cardiac transplantation. Four weeks later she had developed worsen- $\dot{\infty}$ ing symptoms of heart failure despite increasing diuretic therapy. Cardiac catheterisation 3 and angiography showed severe aortic coarc $-\vec{c}$ tation (diameter $3 \mathrm{~mm}$ ) with a peak-to-peak systolic gradient of $40 \mathrm{~mm} \mathrm{Hg}$ between the proximal aortopulmonary segment and descending aorta. Transcatheter balloon $\vec{\ominus}$ dilatation was performed with an $8 \mathrm{~mm}$ bal- $\varphi$ loon (balloon:aortic ratio of $1: 1$ ). There was no residual waist during balloon inflation: stenosis returned after deflation and haemo-⿳亠二口犬 dynamic function did not improve. There was̋ continued deterioration and she was re-venti- $\stackrel{\mathbb{Q}}{\varrho}$ lated because of worsening heart failure. $\overrightarrow{\overrightarrow{0}}$ Clinically there was evidence of increased pul- 3 monary blood flow, presumably related to the obstruction distal to the origin of the pulmonary arteries, which resulted in increased $\vec{\Phi}$ systolic and diastolic pulmonary perfusion pressure. Further surgery was felt to be unde- $\frac{\dot{0}}{3}$ sirable and so she underwent repeat cardiac. catheterisation with stent implantation. Informed consent was obtained from the parents and the procedure was approved by the $\frac{}{2}$ hospital ethics committee.

After aortography (fig 1A) the stent delivery system was passed over an exchange length ${ }^{N}$ 0.018 inch guide wire that had been placedn across the stenosis. The stent itself was anN $8 \mathrm{~mm}$ self-expanding device, $1.5 \mathrm{~cm}$ long (deployed), and mounted on a 5 French shafto (Wallstent, Schneider International). This developmental device is a modification of the $\stackrel{\text { ? }}{?}$ peripheral arterial wallstent system that has been described in detail elsewhere. ${ }^{5}$ The stent? was deployed across the coarcted segment? without difficulty. Care was taken to ensureo that there was minimal protrusion of the device into the descending aorta. Repeat aor-? tography confirmed adequate placement and? excellent anatomical results (fig 1B). There was no residual peak-to-peak pressure gradi? ent between the ascending and descending aorta on pullback.

The patient was given heparin and subsequently warfarin. Her clinical condition rapidly improved and she was weaned from 


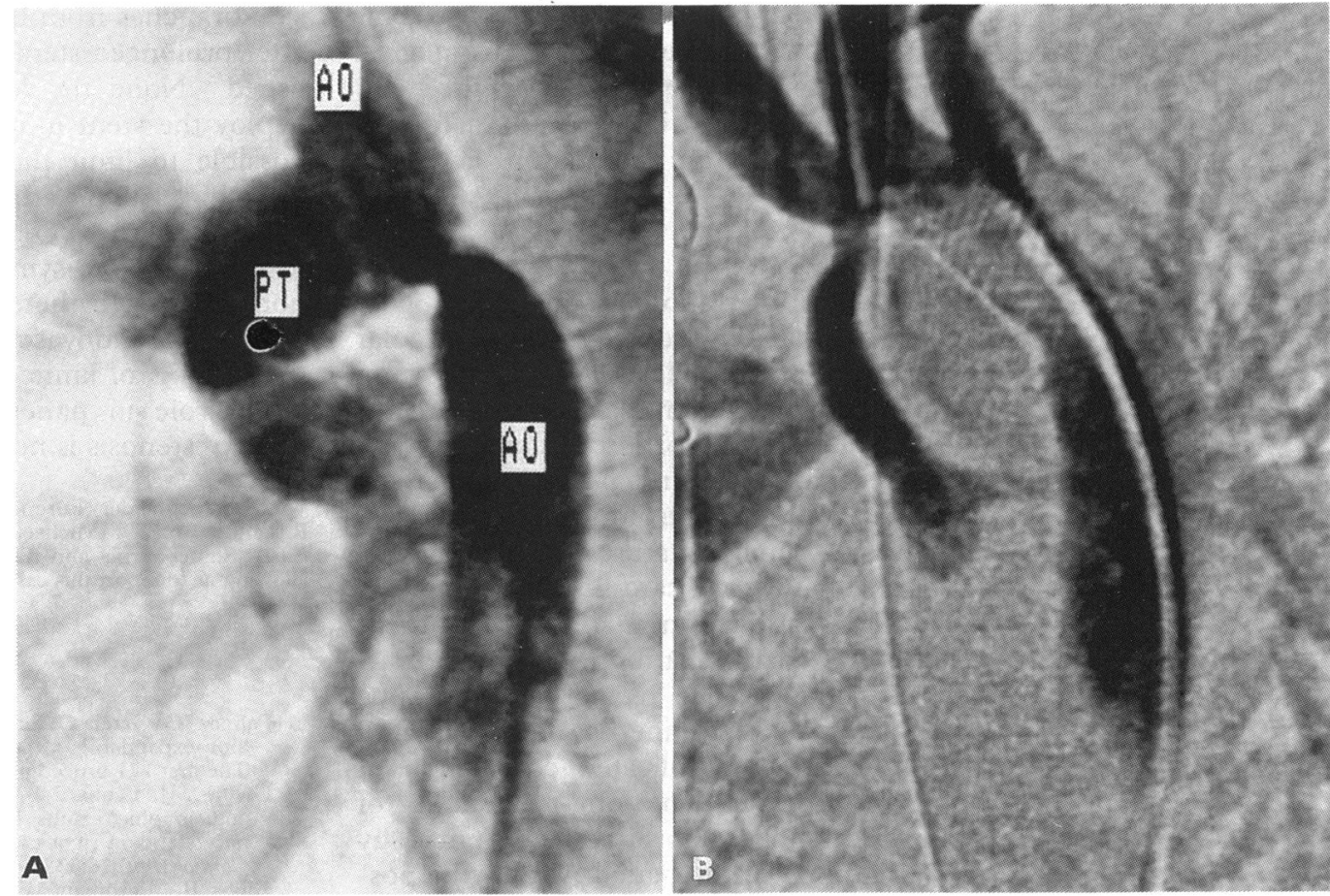

Figure 1 (A) Digital subtraction aortogram showing severe aortic coarctation (diameter $3 \mathrm{~mm}$ ) (see text for details). $A O$, aorta; $P T$, pulmonary trunk.

(B) Digital substraction aortogram of an $8 \mathrm{~mm}$ self-expanding stent after placement. There is complete relief of the coarctation

the ventilator and extubated within 48 hours of the procedure. She was returned to the general ward but five days later suffered a massive aspiration event and required high pressure mechanical ventilation. Sub- sequently bilateral pneumonia and overwhelming sepsis developed and she died 72 hours later. A postmortem examination was performed. Figure 2A shows the gross macroscopical findings. The stent was placed across

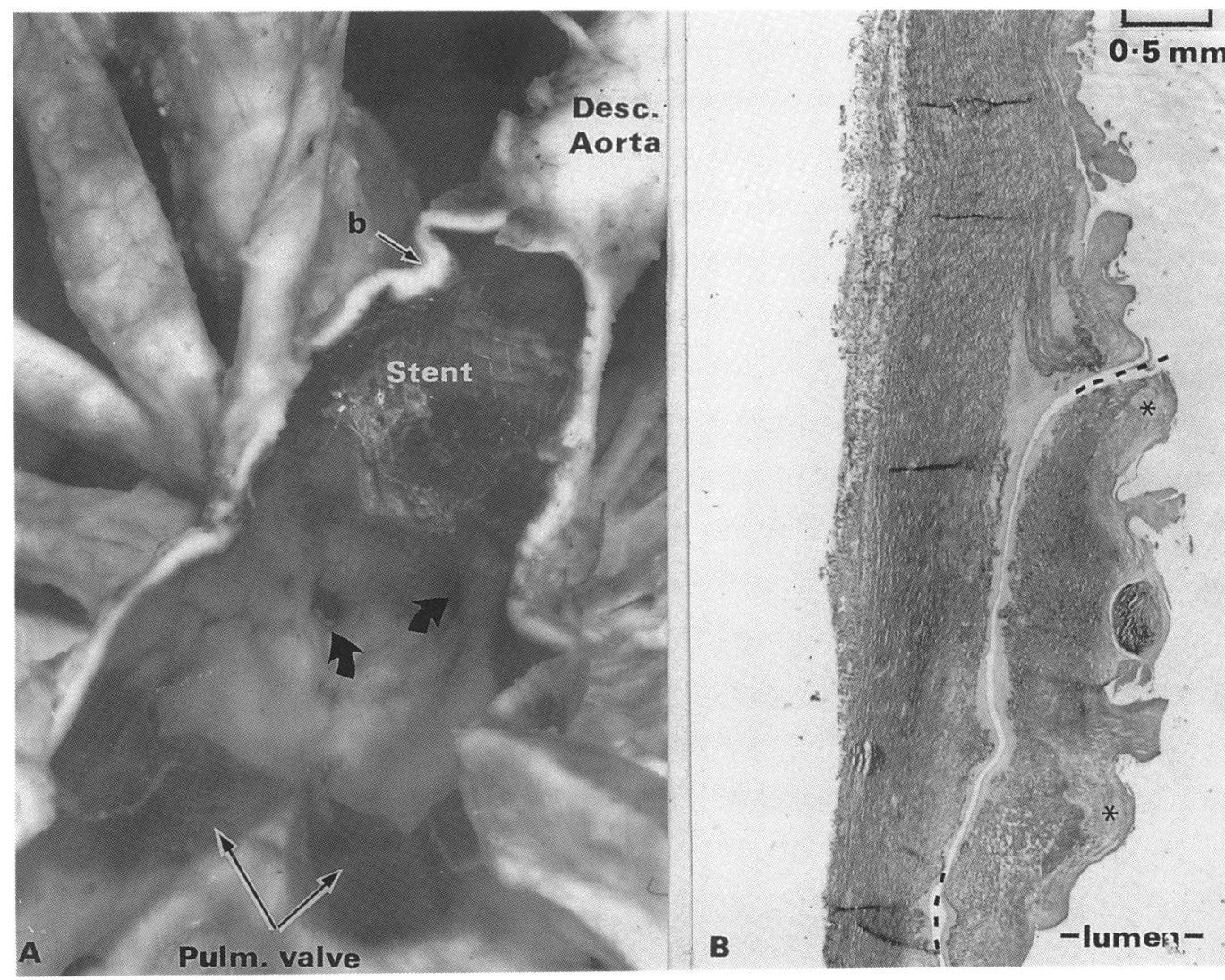

Figure 2 (A) Anterior wall of the pulmonary trunk opened to show the anastomosis with the aorta. The curved arrows indicate the orifice to the left and right pulmonary arteries. The stent is in position across the area of coarctation $\left({ }^{\star}\right)$. $(B)$ Histological through the coarctation lesion showing a dissection (- - ) disrupting the elastic layers of the aortic media. The luminal aspect of the lesion is indented in places showing the impressions made by the stent. The intimal layer ( ${ }^{\star}$ ) is composed of smooth muscle that is continuous with duct tissue (elastic van Gieson stain; original magnification, $\times 10$ ). 
the area of coarctation and there was complete relief of the narrowing. Histological examination (fig 2B) confirmed that the stent traversed the area of circumferential ductal tissue that made up the coarctation shelf.

\section{Discussion}

This case illustrates another potential application of percutaneously deployed endovascular stents in children. ${ }^{3-5}$ Placement of an $8 \mathrm{~mm}$ self-expanding stent across a balloon expandable but undilatable aortic coarctation led to complete anatomical and physiological relief of stenosis and rapid resolution of symptoms. The unique clinical features of our patient, who was to undergo cardiac transplantation in infancy, made the non-surgical treatment of her aortic coarctation both clinically desirable and ethical. The technique cannot be recommended for routine use in infants and children with uncomplicated coarctation of the aorta, however. The long-term utility of stents placed in the aorta will be limited by somatic growth of the patient. It may be possible, if necessary, to dilate further a stent by balloon angioplasty, but ultimately a stent placed in childhood will become stenotic. Biodegradable stents may resolve this difficulty but they are not yet available for clinical use. Also stents in this position could occlude important branch vessels from the aorta. In a previous report there was no demonstrable stenosis or occlusion of spinal arteries after deployment of stents in the dog aorta ${ }^{6}$ and, furthermore, the medium-term patency of side branches from the coronary arteries even after prolonged stent placement is well established. ${ }^{7}$ None the less, we made efforts to deploy the stent in as proximal a position as possible to limit the number of spinal and bronchial arteries affected.

In summary, we showed that it is possible to relieve severe symptomatic aortic coarctation by transcatheter placement of a selfexpanding endovascular stent. Though this approach is of limited clinical utility it clearly has a role in patients in whom long-term relief of stenosis is not required.

We thank Schneider (Europe) for providing the stent, Dr Eric Rosenthal and Dr Michael Rigby for their advice and Dr Elliot Shinebourne and Professor Sir Magdi Yacoub for allowing us to report this case.

Palmaz JC, Garcia O, Schatz RA, et al. Placement of a balloon-expandable intraluminal stents in iliac arteries: The first 171 procedures. Radiology 1990;174:969-75.

2 Levine MJ, Leonard BM, Burke JA, et al. Clinical and angiographic results of balloon-expandable intracoronary stents in right coronary artery stenoses. $f$ Am Coll Cardiol 1990;16:332-9.

3 Gibbs JL, Rothman MT, Rees MR, Parsons JM, et al Stenting the arterial duct: a new approach to palliation Stenting the arterial duct: a new approach to pa

4 O'Laughlin MP, Perry SB, et al. Use of endovascular stents in congenital heart disease. Circulation 1991; stents in con

5 Chatelain P, Meier B, Friedli B. Stenting of superior vena cava and inferior vena cava of symptomatic narrowing after repeated atrial surgery for D-transposition of the great vessels. Br Heart f 1991;664:66-9.

6 Beckman RH, Muller DW, Lupinetti FM, et al. Balloonexpandable stent repair of experimental coarctation of the aorta in dogs [abstr]. Circulation 1991;84 (suppl II): 513.

7 Schatz RA, Palmaz JC, Tio FO, et al. Balloon-expandable intracoronary stents in the adult dog. Circulation 1987; 76:450-7. 